\title{
Enhancement of bacteriolysis of Shuffled phage PhiX174 gene E
}

\author{
Shen-ye Yu, Wei Peng, Wei Si, Lu Yin, Si-guo Liu*, Hui-fang Liu, Hai-ling Zhao, Chun-lai Wang, Yue-hong Chang \\ and Yue-zhi Lin
}

\begin{abstract}
Bacterial ghosts that are generated using the regulated PhiX174 lysis gene E offer a new avenue for the study of inactivated vaccines. Here, we constructed a library of mutant gene $E$ using a gene-shuffling technique. After screening and recombination with the prokaryotic non-fusion expression vector pBV220, two lysis plasmids were selected. Among which, a novel mutant $\mathrm{E}$ gene (named $\mathrm{mE}$ ), consisting of a 74-bp non-encoding sequence at 5'-end and a 201-bp gene $\Delta \mathrm{E}$, significantly increased the lysis effect on prokaryotic Escherichia coli and Salmonella enteritidis. Moreover, lysis efficiency, as measured by the $\mathrm{OD}_{600}$ value, reached $1.0\left(10^{9} \mathrm{CFU}\right)$, avoiding the bottleneck problem observed with other bacterial lysis procedures, which results in a low concentration of bacteria in suspension, and consequent low production of bacterial ghosts. Our results may provide a promising avenue for the development of bacterial ghost vaccines.
\end{abstract}

\section{Introduction}

The lysis gene E of coliphage PhiX174 encodes a 91amino acid (aa) residue protein of approximately $10 \mathrm{kDa}$ that mediates inhibition of peptidoglycan biosynthesis of Gram-negative bacteria membrane[1]. This facilitates lysis from changes in osmotic pressure, leaving an empty bacterial body lacking cytoplasm and nucleic acids, which is called a bacterial ghost (BG) [2]. BGs retain an intact bacterial surface structure and integrated antigen proteins, and can be generated without harsh physical or chemical inactivation methods. BGs can be used directly as vaccines, as they exhibit good immunogenicity and provide effective inducible immunoprotection. Furthermore, inserting the exogenous antigen protein into the outer, inner, or periplasmic membranesis is relatively simple, and genetic engineering can be used to construct recombinant multivalent BG vaccines. Thus, BGs have been widely applied in the development of new vaccines [3-5].

In a previous study, we constructed a lysis plasmid pBV-E from the PhiX174 lysis gene E and the plasmid pBV220. Upon transformation of E. coli strain DH5 $\alpha$, lysis efficiency was $98 \%$. Using parameters from previous

\footnotetext{
* Correspondence: siguo_liu@yahoo.com.cn

State Key Laboratory of Veterinary Biotechnology, Harbin Veterinary Research Institute of Chinese Academy of Agricultural Science, Harbin 150001, China
}

studies, the optical density (OD) value at $600 \mathrm{~nm}$ of the bacterial suspension was maintained at $0.4\left(10^{6} \mathrm{CFU}\right)$ by adding chloramphenicol $(50 \mu \mathrm{g} / \mathrm{mL})$ to inhibit bacterial proliferation [6]. Nonetheless, low lysis efficiency and ghost production have been the key technical obstacles that have prevented the large-scale production and industrialization of BG vaccines.

To address these technical problems, the current study focused on the function of the bacteriophage PhiX174 lysis gene E. Mutations were introduced by gene shuffling, and after screening and recombination with the pBV220 vector, novel mutants of lysis E gene (named $\mathrm{mEs}$ ) were selected and the lysis plasmid $\mathrm{pBV}$-mEs were characterized. Plasmids pBV-mEs may be a useful tool for producing BGs of Gram-negative bacteria such as E. coli and Salmonella enteriditis.

\section{Materials and methods}

\section{Plasmids and bacterial strains}

Plasmid pBV220 was a kind gift from Professor Guihong Zhang of South China Agricultural University. It is a prokaryotic non-fusion expression vector with multiple cloning sites (MCS) adjacent with Shine-Dalgarno (SD) sequence, and a high-copy number plasmid with a gene for ampicillin resistance and a $\lambda \mathrm{PL} / \mathrm{PR}$-cI857 temperature-sensitive system that can express target gene inserted in MCS at $42^{\circ} \mathrm{C}$ (Figure 1). E. coli strain JL09 


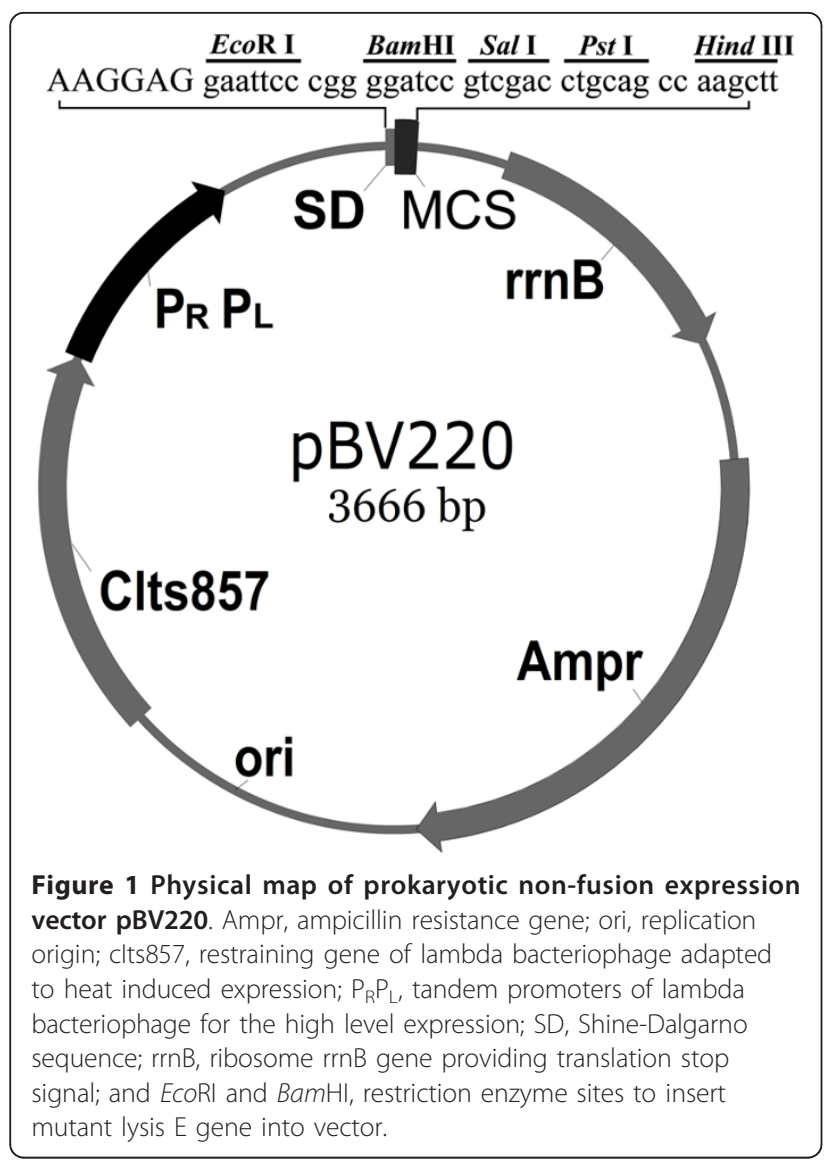

and S. enteriditis strain DH09 were isolated and identified in our lab. Bacteriophage PhiX174 was purchased from NEB (Beverly, MA). E. coli strain DH5 $\alpha$ was maintained in our laboratory.

\section{Cloning of bacteriophage PhiX174 lysis gene E}

Primers were designed according to the sequence of PhiX174 lysis gene E [7] in Genbank and synthesized by Invitrogen Inc. (Shanghai). Upstream primer LysisE-U: 5'-AGG GAA TTC ATG GTA CGC TGG ACT TTG TGG-3' (EcoR I restriction site was underlined), downstream primer LysisE-L: 5'-AGG GGA TCC GAG CTC TCA CTC CTT CCG-3'(BamH I restriction site was underline). Gene E was amplified using PhiX174 doublestranded DNA as template, in a $50 \mu \mathrm{L}$ reaction with amplification cycle parameters: $5 \mathrm{~min}$ at $95^{\circ} \mathrm{C} ; 30$ cycles of $30 \mathrm{~s}$ at $94^{\circ} \mathrm{C}, 30 \mathrm{~s}$ at $59^{\circ} \mathrm{C}, 1 \mathrm{~min}$ at $72^{\circ} \mathrm{C}, 5 \mathrm{~min}$ at $4^{\circ}$ C. PCR products were resolved on $0.9 \%$ agarose gels, and the 300-bp gene E fragment was extracted with a gel extraction kit (Shanghai Watson Biotech Co., China).

\section{DNA shuffling in lysis gene $E$}

DNA shuffling was carried out according to Evans [8] with minor modifications. The purified gene $\mathrm{E}$ was digested with DNase I and fragments of 10-50 bp were gel-purified and amplified by primerless PCR. Reaction parameters were: 45 cycles of $94^{\circ} \mathrm{C}$ for $30 \mathrm{~s}, 40^{\circ} \mathrm{C}$ for $30 \mathrm{~s}$, and $72^{\circ} \mathrm{C}$ for $30 \mathrm{~s}$. PCR products were analyzed on a $2 \%$ agarose gel and used as PCR templates using LysisE-U and LysisE-L as primers, with parameters: $95^{\circ} \mathrm{C}$ for $5 \mathrm{~min} ; 30$ cycles of $94^{\circ} \mathrm{C}$ for $30 \mathrm{~s}, 59^{\circ} \mathrm{C}$ for $30 \mathrm{~s}, 72^{\circ} \mathrm{C}$ for $30 \mathrm{~s}$, and extension at $72^{\circ} \mathrm{C}$ for $5 \mathrm{~min}$. Products were resolved on $0.9 \%$ agarose gels and extracted as above.

\section{Construction, screening, and transformation of clinical} strains and lysis plasmid library efficiency comparison Purified EcoR I- and BamH I-digested fragments of mutant gene E were inserted into pBV220 and transformed into DH5 $\alpha$ competent cells, which were spread on LB plates containing ampicillin. Single colonies were picked and screened by colony PCR with primers LysisE-U and LysisE-L. Positive clones were cultured at $37^{\circ} \mathrm{C}$ and sent to Invitrogen Inc. (Shanghai) for sequencing. Expression of lysis gene $\mathrm{E}$ or mutants of $\mathrm{E}$ was induced at $42^{\circ} \mathrm{C}$. After bacteriolysis, the bacterial suspension was diluted to an appropriate concentration and spread on LB containing ampicillin. After $37^{\circ} \mathrm{C}$ for $12 \mathrm{~h}$, colonies were counted and the results expressed as $\mathrm{CFU} / \mathrm{ml}$. The lysis rate was calculated using the following formula: lysis rate $=(1-\mathrm{CFU}$ after induction $/ \mathrm{CFU}$ before induction) $\times 100 \%$. Plasmids with high lysis rates were selected and sequenced, and those with the highest lysis rate were electroporated into the clinically isolated bacterial strains E. coli JL09 and S. enteriditis DH09. Analysis, and calculation and comparison of lysis rates used the protocol above. The corresponding bacterial strain harboring pBV220 was used as control.

\section{Scanning electron microscopy (SEM) and transmission electron microscopy (TEM)}

Sample preparation for SEM (model, JSM-6510LV, Japan) was by centrifugation of a induced bacterial suspension at $3000 \times g$ for $10 \mathrm{~min}$, before fixing with $2.5 \%$ glutaraldehyde ( $\mathrm{pH} 7.2$ ) for $1.5 \mathrm{~h}$ at $4^{\circ} \mathrm{C}$. Samples were washed three times for $10 \mathrm{~min}$ with $0.01 \mathrm{M}$ phosphatebuffered saline (PBS). Dehydration steps were $10 \mathrm{~min}$ each in $50 \%, 70 \%, 80 \%$, and $90 \%$ ethanol, a $1: 1$ mixture of $100 \%$ ethanol and tert-butanol, and pure tert-butanol. After lyophilization for approximately $4 \mathrm{~h}$, samples were placed on the microscope platform, coated with a layer of heavy metal and examined.

Sample preparation for TEM (microscope model, JEM 1200 EX, Japan) was as above, except fixing was for 2-3 h. Samples were washed as above, and fixed with $2 \%$ osmic acid for $1.5 \mathrm{~h}$, followed by three washings of $10 \mathrm{~min}$ each with $0.1 \mathrm{M}$ PBS. Dehydration steps were $10 \mathrm{~min}$ each in $50 \%, 70 \%, 80 \%, 90 \%$, and $100 \%$ ethanol. Samples were immersed in 1:1, 1:2, or 1:3 mixtures of SPI-Pon 812 resin (emicron) and acetone, before immersing overnight in 
100\% 812 resin. Resin-soaked sample blocks were polymerized at $70^{\circ} \mathrm{C}$ for $48 \mathrm{~h}$, and samples sectioned and stained with uranyl acetate and lead citrate, before microscopy.

\section{Results}

\section{PCR amplification of lysis gene E and DNA shuffling}

The size of the PCR-amplified lysis gene E fragment was $276 \mathrm{bp}$, as expected (Figure 2A1). The purified fragment was digested with DNase I, and the digested fragments ran as a smear (Figure 2A2). Fragments of 10-50 bp were gel-purified and amplified by primerless PCR, and appeared as diffuse bands of $100-300$ bp on a $1 \%$ agarose gel (Figure 2A3). Primerless PCR products were used as a template for primed PCR amplification, yielding a single 276-bp band on a $1 \%$ agarose gel. This band was the shuffled, mutated gene E (Figure 2A4).

\section{Shuffled gene E lysis plasmids, and screening of high lysis efficiency plasmids}

Gel-purified mutants fragments were digested with EcoR $\mathrm{I}$ and Bam H I and inserted into the vector pBV220, and transformed into E. coli DH5 $\alpha$. Selection on LB containing ampicillin generated a lysis plasmid library of gene $\mathrm{E}$ mutants.

After large-scale screening, six stable strains were obtained. Lysis plasmids No. 3 (p3) and No. 4 (p4) had the highest lysis rates, at $99.999 \%$. No lysis was observed in control group pBV220. Sequencing and comparison indicated that $\mathrm{p} 3$ and $\mathrm{p} 4$ share $100 \%$ identity with each other and share $98 \%$ identity with $\mathrm{pBV}$-E and other four non-lysis plasmids (Figure 2B). A single nucleotide deletion was found at the $5^{\prime}$-end of the lysis gene $\mathrm{E}$ sequence in $\mathrm{mE} 3$ and $\mathrm{mE} 4$, which converts the original wild-type $\mathrm{E}$ gene into a 74-bp non-coding region and a 201-bp gene $\Delta \mathrm{E}$. Then $\Delta \mathrm{E}$ was amplified and inserted into EcoR I- and BamH I sites, the plasmid pBV- $\Delta \mathrm{E}$ had lysis rate of $56.427 \%$.(Figure $2 \mathrm{C}$ ) Thus, this 74 -bp region is likely to play an important role in lysis enhancement. We further investigated plasmid p4 (named pBV-mE), which had the highest lysis rates.

\section{Comparison of the pBV-mE transformed E. coli lysis curve at different $O D$ values}

The results of lysis kinetics experiments showed that pBV-mE had very high lysis efficiency against DH5 $\alpha$

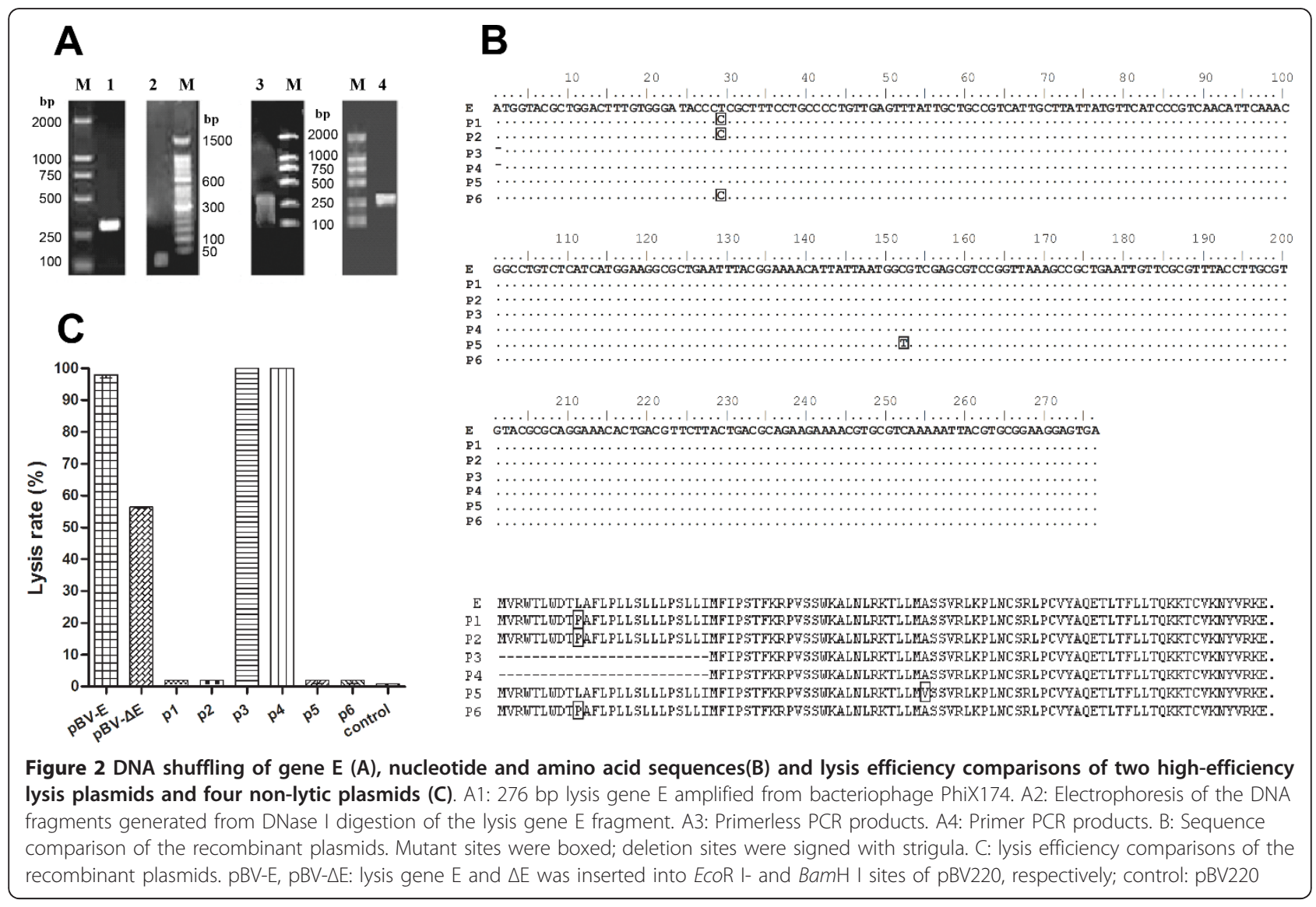




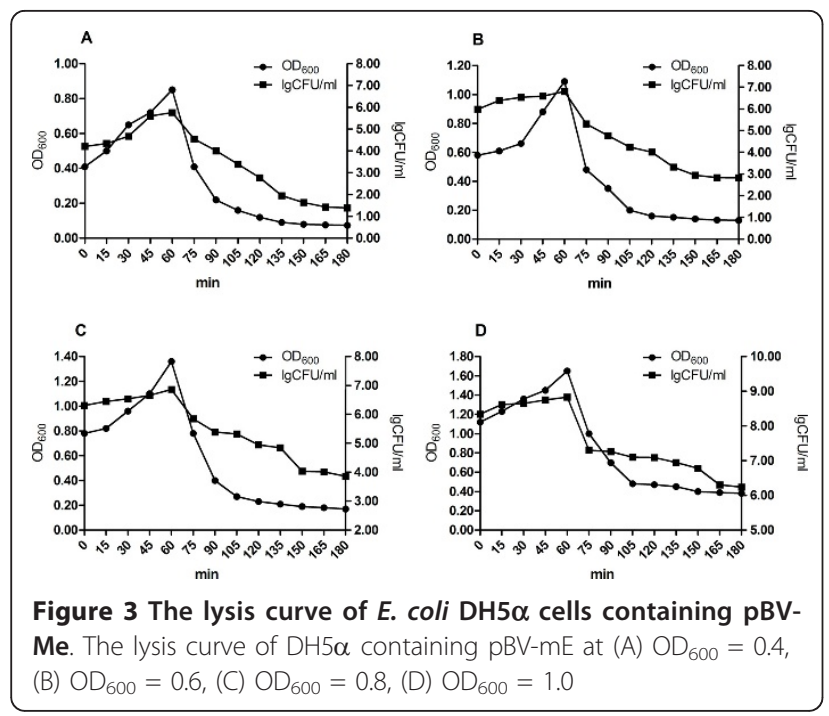

cells. Effective lysis occurred at all tested OD values (0.4, $0.6,0.8$ and 1.0), and progressed rapidly, with lysis completed within $2 \mathrm{~h}$ (Figure 3).

\section{Comparison of lysis efficiencies of clinically isolated bacteria transformed with $\mathrm{pBV}$-mE}

Plasmid pBV-mE had the same lysis effect on both E. coli and S. enteriditis. Comparison of SEM and TEM photographs of the cell surface of E. coli and S. enteriditis before and after lysis showed that BGs retained the basic cell morphology of the bacterial cells, but displayed obvious surface wrinkles from the loss of intracellular contents. Arrow c in Figure 4E, and arrow d in Figure 4F indicate lysis tunnels in the S. enteriditis BGs, located mainly at the cell poles. Ejection of the intracellular contents from the lysis tunnels can be seen, consistent with a previous report [9], although the BGs in our study exhibited relatively complete outer membranes with little change in morphology.

\section{Discussion}

Genetic inactivation of Gram-negative bacteria by inducing a regulated bacteriophage PhiX174 lysis gene E provides a new avenue for inactivated vaccine research $[4,10]$. E-protein-mediated lysis has already been used to investigate many types of bacterial ghosts, suggesting that it may be applicable to any of the Gram-negative bacteria [3,11-16]. Moreover, bacterial ghosts can be used as vehicles for the delivery of exogenous antigens or drugs.

In this study, a 275-bp mE gene was selected from a library of mutant lysis gene E generated by DNA shuffling. The mutant contained a 74-bp non-encoding sequence and a 201-bp lysis gene $\Delta \mathrm{E}$. A lysis plasmid containing the $\mathrm{mE}$ gene driven by dual $\mathrm{pR}$ and $\mathrm{pL}$

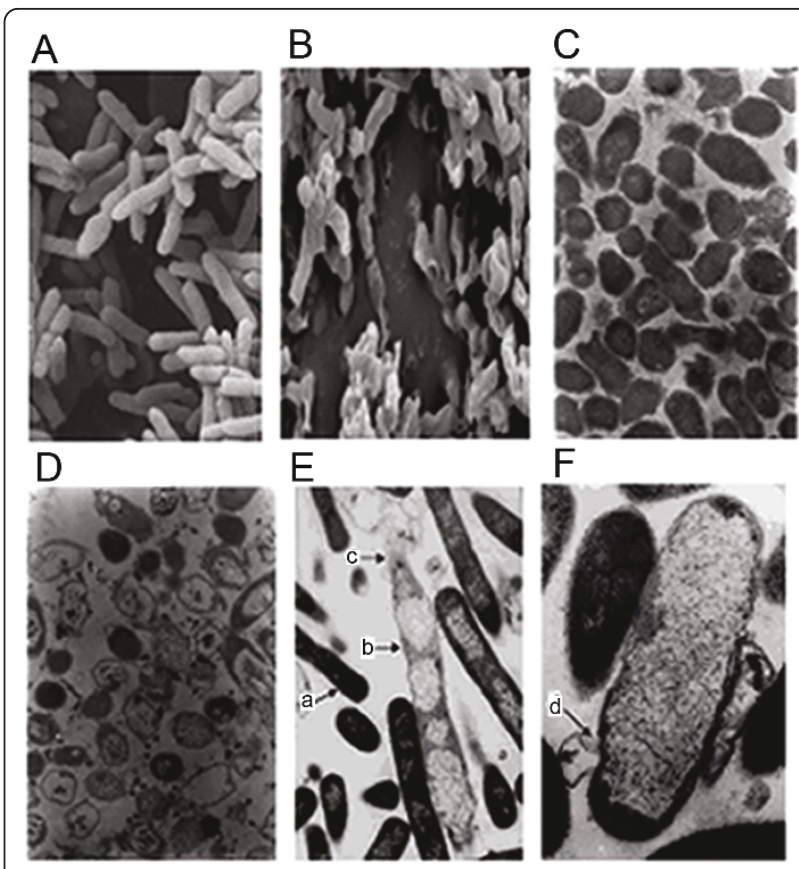

Figure 4 Electron microscopy analysis of $E$. coli and $S$. enteriditis before and after lysis. A: Morphology of wild-type $E$. coli under scanning electron microscopy: intact and healthy. B: Morphology of $E$. coli after lysis under scanning electron microscopy: shrinkage observed. C: Morphology of wild-type S. enteriditis under transmission electron microscopy: even electron density. D: Morphology of S. enteriditis ghosts after lysis under transmission electron microscopy: uneven electron density, vacuolar. E, F: Observation of the ejection of the intracellular contents from S. enteriditis under transmission electron microscopy. a. S. enteriditis before lysis $(12,000 \times$ magnification). b. S. enteriditis after lysis, bacterial ghost $(12,000 \times)$. c. Lysis tunnels on ghosts $(12,000 \times)$. $d$. Lysis tunnels on ghosts $(30,000 \times)$

promoters significantly increased lysis efficiency over the 95\% efficiency in the same E. coli strain with previously reported constructs with a single $\mathrm{pR}$ or $\mathrm{pL}$ promoter [17]. The lysis efficiency of the plasmids was not affected by bacterial concentration. Bacteria with an $\mathrm{OD}_{600}$ of $1.0\left(10^{9} \mathrm{cfu}\right)$ are sufficiently concentrated for vaccination, and the observed $99.999 \%$ lysis efficiency of $\mathrm{pBV}-\mathrm{mE}$ was higher than another lysis plasmid, pBV-E (98\%) that we previously generated [6]. The new lysis plasmid eliminates the lysis requirement that the OD of the bacterial culture be between 0.4 and 0.6 , which has been a key technical problem for large-scale vaccine production. Therefore, the current data indicate a promising avenue for BG vaccine research.

While both E. coli and Salmonella showed good lysability, the lysis efficiency of protein $\mathrm{mE}$ was significantly higher than lysis protein E in both bacteria. Previous studies showed that the N-terminal 51 aa of PhiX174 lysis protein E are necessary for lysis activity [18] and the lysis activity localized to the N-terminal 29 aa [19]. 
Another study suggested that the activity was associated with the N-terminal 35 aa, including a hydrophobic area (a potential transmembrane region) that is essential for the lysis function of protein E [20]. The C-terminus of protein $\mathrm{E}$ is important for conformational stability and regulation of lysis functions [21]. It was proposed that, at an early stage of bacteriolysis, a conformational isomerism probably occurs at proline residue 21 (P21) in the first transmembrane $\alpha$-helix of protein E. Mutations of P21 to alanine, glycine, serine, or valine result in an unstable protein, and thus affect $\mathrm{E}$ protein levels in vivo and the loss of lysis function. The initiation of cell division, rather than any specific functions of the septotome has been shown to play a pivotal role in protein Emediated Gram-negative bacteriolysis [22].

It is interesting that our results differ from those of previous studies. For plasmid p1 and p6 with observed enhancement of lysis effect, single deletion of A from the 5'-end of E gene converted the first 75-bp encoding sequence to 74-bp non-encoding region, which resulted in the loss of first 25 aa in wild-type E protein. Considering the length of the $\mathrm{mE}$ protein is sufficient for crossing the membrane, we propose that lysis activity is not located only within the first 29 aa of protein E, but rather that sequences downstream of aa 25 also have lysis activity. However, so far as now, the detailed mechanism of E-mediated lysis is still obscure, let alone the $\mathrm{mE}$ protein. Therefore, we would work on the assumption as follows.

It should be pointed out that, after sequence comparison, we found the similarity of this 74-bp sequence with many well-known viral enhancers (Figure 5). Moreover, the first five bases (TGGTA) of the 74-bp is only one nucleotide different from the minus-35 region of the RpoN (alternate sigma factor) consensus (TGGCA). It is also only one nucleotide different from the minus-35 sequence of the strong promoter of the recA gene (TGATA). Therefore, one possible explanation for this enhancement is that the 74-bp sequence dramatically

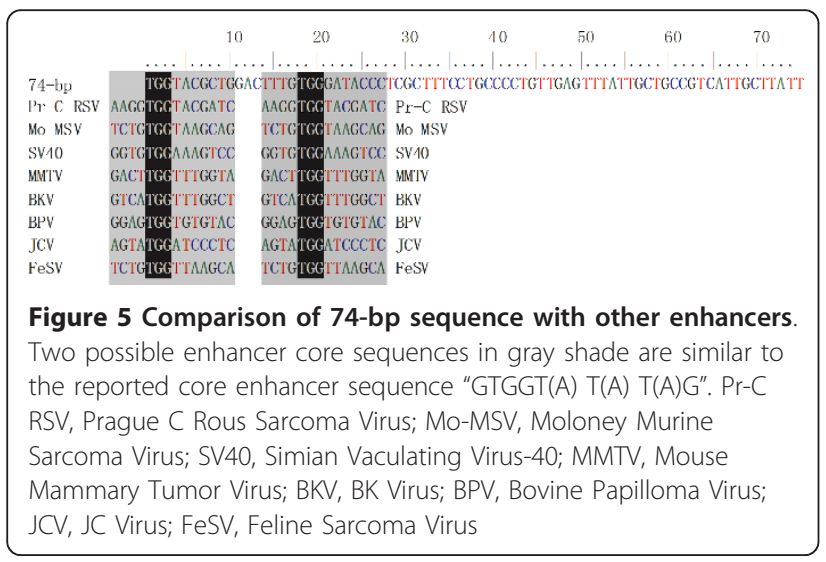

improves the transcription efficiency of $\mathrm{pBV}-\mathrm{mE}$, increases production of the $\Delta \mathrm{E}$ protein and provides excess protein molecule for lysis. Another explanation is the 74-bp sequence may positively regulate the replication of lysis plasmids pBV-mEs. All lysis plasmids constructed with mutant E genes (pBV-mEs) had copy numbers higher than that of pBV-E (data not shown). Lin et al. reported that copy numbers of pUC family plasmids are much higher than other plasmids with a pMB1 or colE1 origin. This is due to a single point mutation in the pUC plasmids that can cause a temperature-dependent alteration in the secondary structure of RNA II[23].

In conclusion, the results from our study could indicate a potentially new avenue to solve two key problems in $B G$ research and vaccine production: low bacterial concentration and low BG production. More work is needed to confirm the above assumptions about $\mathrm{mE}$ gene. Identification and characterization of 74-bp enhancer or enhance-like or promoter-like element is carrying out.

\section{Acknowledgements}

This work was supported by a grant from National "863" program (2011AA10A210).

\section{Authors' contributions}

SYY did laboratory testing, analyzed the test results, wrote and edited the manuscript. WP and WS did laboratory testing and co-wrote the manuscript. LY, HFL, HLZ, CLW, YHC and YZL did laboratory testing. SGL is the leader of the study group and organized the overall project and helped edit the manuscript. All the authors read and approve the final manuscript.

\section{Competing interests}

The authors declare that they have no competing interests.

Received: 19 November 2010 Accepted: 6 May 2011

Published: 6 May 2011

\section{References}

1. Bernhardt TG, Roof WD, Young R: Genetic evidence that the bacteriophage phi X174 lysis protein inhibits cell wall synthesis. Proc Natl Acad Sci USA 2000, 97(8):4297-4302.

2. Witte A, Blasi U, Halfmann G, Szostak M, Wanner G, Lubitz W: Phi X174 protein E-mediated lysis of Escherichia coli. Biochimie 1990, 72(23):191-200.

3. Jalava K, Hensel A, Szostak M, Resch S, Lubitz W: Bacterial ghosts as vaccine candidates for veterinary applications. J Control Release 2002, 85(1-3):17-25.

4. Eko FO, Witte A, Huter V, Kuen B, Fürst-Ladani S, Haslberger A, Katinger A, Hensel A, Szostak MP, Resch S, et al: New strategies for combination vaccines based on the extended recombinant bacterial ghost system. Vaccine 1999, 17(13-14):1643-1649.

5. Kudela P, Paukner S, Mayr UB, Cholujova D, Schwarczova Z, Sedlak J, Bizik J, Lubitz W: Bacterial ghosts as novel efficient targeting vehicles for DNA delivery to the human monocyte-derived dendritic cells. J Immunother 2005, 28(2):136-143.

6. Chang YH, Liu SG, Wang CL, Liu HF, Si W: Preparation of Actinobacillus pleuropneumoniae Ghosts. Chin J Pre Vet Med 2008, 30:674-677, (In Chinese).

7. Witte A, Wanner G, Blasi U, Halfmann G, Szostak M, Lubitz W: Endogenous transmembrane tunnel formation mediated by phi X174 lysis protein $\mathrm{E}$. J Bacterio/ 1990, 172(7):4109-4114. 
8. Evans GA, Margulies DH, Shykind B, Seidman JG, Ozato K: Exon shuffling: mapping polymorphic determinants on hybrid mouse transplantation antigens. Nature 1982, 300(5894):755-757.

9. Mayr UB, Haller C, Haidinger W, Atrasheuskaya A, Bukin E, Lubitz W, Ignatyev G: Bacterial ghosts as an oral vaccine: a single dose of Escherichia coli 0157:H7 bacterial ghosts protects mice against lethal challenge. Infect Immun 2005, 73(8):4810-4817.

10. Szostak MP, Hensel A, Eko FO, Klein R, Auer T, Mader H, Haslberger A, Bunka S, Wanner G, Lubitz W: Bacterial ghosts: non-living candidate vaccines. J Biotechnol 1996, 44(1-3):161-170.

11. Zhang RP, Zhang ZS: Advances on the novel drug deliver system: bacterial ghost. Prog Bioche Biophys 2006, 33:622-626.

12. Eko FO, Lubitz W, McMillan L, Ramey K, Moore TT, Ananaba GA, Lyn D, Black CM, Igietseme JU: Recombinant Vibrio cholerae ghosts as a delivery vehicle for vaccinating against Chlamydia trachomatis. Vaccine 2003, 21(15):1694-1703.

13. Jechlinger W, Haller C, Resch S, Hofmann A, Szostak MP, Lubitz W: Comparative immunogenicity of the Hepatitis B virus core 149 antigen displayed on the inner and outer membrane of bacterial ghosts. Vaccine 2005, 23(27):3609-3617.

14. Panthel K, Jechlinger W, Matis A, Rohde M, Szostak M, Lubitz W, Haas R: Generation of Helicobacter pylori ghosts by PhiX protein E-mediated inactivation and their evaluation as vaccine candidates. Infect Immun 2003, 71(1):109-116.

15. Hensel A, Huter V, Katinger A, Raza P, Strnistschie C, Roesler U, Brand E, Lubitz W: Intramuscular immunization with genetically inactivated (ghosts) Actinobacillus pleuropneumoniae serotype 9 protects pigs against homologous aerosol challenge and prevents carrier state. Vaccine 2000, 18(26):2945-2955.

16. Marchart J, Dropmann G, Lechleitner S, Schlapp T, Wanner G, Szostak MP, Lubitz W: Pasteurella multocida- and Pasteurella haemolytica-ghosts: new vaccine candidates. Vaccine 2003, 21(25-26):3988-3997.

17. Wang N, Zeng WK, Guo G, Zou QM: Preparation and characterization of $E$. coli "bacterial ghost". Med J Chin PLA 2005, 30:226-228.

18. Bläsi U, Lubitz W: Influence of C-terminal modifications of phi X174 lysis gene $\mathrm{E}$ on its lysis-inducing properties. J Gen Virol 1985, 66(Pt 6):1209-1213.

19. Young KD, Young R: Lytic action of cloned phi X174 gene E. J Virol 1982, 44(3):993-1002.

20. Buckley K, Hayashi M: Lytic activity localized to membrane-spanning region of phi X174 E protein. Mol Gen Genet 1986, 204(1):120-125.

21. Schüller A, Harkness RE, Ruther U, Lubitz W: Deletion of C-termInal amino acid codons of PhiX174 gene E: effect on its lysis inducing properties. Nucleic Acids Res 1985, 13(11):4143-4153.

22. Henrich B, Lubitz W, Plapp R: Lysis of Escherichia coli by induction of cloned phi X174 genes. Mol Gen Genet 1982, 185(3):493-497.

23. Lin CS, Chen WT, Wong TT: High copy number of the pUC plasmid results from a Rom/Rop-suppressible point mutation in RNA II. Mol Microbiol 1992, 6:3385-3393.

doi:10.1186/1743-422X-8-206

Cite this article as: Yu et al:: Enhancement of bacteriolysis of Shuffled phage PhiX174 gene E. Virology Journal 2011 8:206.

\section{Submit your next manuscript to BioMed Central and take full advantage of:}

- Convenient online submission

- Thorough peer review

- No space constraints or color figure charges

- Immediate publication on acceptance

- Inclusion in PubMed, CAS, Scopus and Google Scholar

- Research which is freely available for redistribution

Submit your manuscript at www.biomedcentral.com/submit 